\title{
Obstacles in the Utilisation of Maternal Health Care Services in Murarai-II C.D. Block, Birbhum District, West Bengal, India
}

\author{
Alokananda Ghosh ${ }^{+*}$ and Dr. Biswaranjan Mistri ${ }^{\top}$
}

\begin{abstract}
Improving maternal health was one of the eight Millennium Development Goals (MDGs) and now it is one of the targets of 17-point Sustainable Development Goals (SDGs). The utilisation of Maternal Health Care Services (MHCSs) is a complex phenomenon and it is influenced by several factors, like-health care seeking behaviour of the cohorts belonging to different socio-economic and cultural background, distance of the facility centres, type and conditions of the roads including undulating surface, transportation cost, type and availability of transportation mode along with the factors related to the accountability and surveillances of the health care services. Therefore, clear understanding and discussion is needed to draw an association between MHCSs and its influential factors. The objectives of the study are to estimate the impact of accessibility on the underserved status of MHCSs and on the utilisation of MHCSs through paucity index. In addition, the study aims to evaluate the causal relationships between underserved situation and obstacle score with the paucity index of MHCS utilisation.

The empirical observation unfolds that the provision and utilisation of MHCSs are strongly dependent on accessibility and distance. The situation is aggravating for proper delivery of services, which is responsible for the increasing obstacle score and paucity index, especially in remote sub- centres of Murarai-II C.D. Block of Birbhum District.

Key words: Maternal Health Care Services (MHCSs), Accessibility Index, Underserved Scenario, Paucity Index, Postnatal Cases, West Bengal, India
\end{abstract}

\footnotetext{
${ }^{+}$UGC-JRF, Department of Geography, The University of Burdwan, 713104, Email: alokanandaghosh04@gmail.com

* Corresponding Author

'̇ Assistant Professor, Department of Geography, The University of Burdwan,713104,Email: brmistri@gmail.com (C) 2017 Ghosh and Mistri. This is an Open Access article distributed under the terms of the Creative Commons Attribution License (http://creativecommons.org/licenses/by/2.0), which permits unrestricted use, distribution, and reproduction in any medium, provided the original work is properly cited.
} 


\section{Introduction}

Maternal health is not a "women's issue" (Machel, 2010:4). It is about the integrity of communities, societies and nations, the wellbeing of all the men, women, boys and girls whose own prospects in life depend upon healthy women and mothers (Machel, 2010). Health of a family depends very much on the health condition of the mother (Chalkey, 2006). Maternal health is defined by the World Health Organisation (WHO) as the health of women during pregnancy, childbirth and postpartum period (Global Concerns Classrooms, 2013). In developing countries, a woman dies from complications related to pregnancy and childbirth every ninety seconds; nearly 1,000 women die every day (Obaid, 2011).Developing regions account for approximately 99\% (302000) of the global maternal deaths in 2015, with sub-Saharan Africa alone accounting for roughly 66\% (201000), followed by Southern Asia (66000).At the country level, Nigeria and India are estimated to account for over one third of all maternal deaths worldwide in 2015, with an approximate 58,000 maternal deaths (19\%) and 45,000 maternal deaths (15\%) respectively (World Bank Group 2015).More than 500,000 women die every year in childbirth or from pregnancy-related complications. Virtually all (99 percent) of these maternal deaths occur in low-income countries (Paruzzolo et al. 2010).The absolute number of women dying due to complications during pregnancy and child birth has decreased by 45\% from an estimated 523000 in 1990 to 289000 in 2013. Direct obstetric causes, notably haemorrhage $(27 \%)$, hypertensive diseases of pregnancy (14\%) and sepsis (11\%) continue to be the leading causes of maternal death (WHO, 2015).Life time risk of maternal death is an indicator which combines both mortality and fertility experience (Datta\& Manna, 2012). The risk is higher in poor communities, in rural, resource poor and geographically difficult areas (Poonam, K. S. 8th March, 2016). While there are numerous factors responsible for these kinds of anguish events, the study focuses on those factors that affect the interval between the onset of obstetric complications and its outcome (Thaddeus \& Maine, 1994). Rugged, undulating surface, rough road conditions, inadequate mode of transportation, lack of service facility specially in the emergency period, negligence in service seeking behaviour driven by illiteracy and less awareness are the responsible factors behind many of the en-route fatalities, like transit delivery leading to maternal death, miserable obstetric outcome, etc. (Masuma \& Bangser, 2004). Delays in health care seeking and availing facility at proper time are the most common scenario in rural areas, yet the literature are not systematically documented on the said perspective (Thaddeus \& Maine, 1994). Literature related to the maternal health care service have mainly focused on the usersproviders' relationship in provision and utilisation of health care services but in most cases they have failed to identify the en-route causalities behind a fatal health event. For instance, long distance from the facility, rough road, undulating surface, rugged terrain, excessive transportation cost, inadequate mode of transportation, etc. Literature is again weak in identifying the impact of distance on the health care seeking behaviour of the cohort and prevailing influence zone of the healthcare service centres. Paucity of literature on the said perspectives is the driving forces behind the initiation of the present investigation. The work has been outlined according to the objectives that have been carried out to accomplish the knowledge gaps in the previous surveyed literature.

The study is structured as follows-it begins with a brief background on issues linked to maternal healthcare services and its obstacles. This is followed by a discussion on the methodological issues undertaken for this research. Following this, the work presents its findings under the heading 'results and discussions'.

\section{Background}

Post-independence India has developed a three-tier healthcare-delivery system to reach 
out to the remote areas to provide primary healthcare at the village level, secondary healthcare at the sub-district and district level, and tertiary healthcare at the regional level, but the rural areas show less use of healthcare services than the urban areas. (Vora et al., 2009; Sarma and Bhattacharyya, 2015).The primary healthcare services are the most indispensable factors for maintaining population health, especially in the rural areas, because it is comparatively less expensive than specialised services and can be provided to the mass on a large scale if properly distributed (Divya et al., 2014; Sarma and Bhattacharyya, 2015). But the insufficient skilled and semiskilled human resources decrease the utilisation of the healthcare services in the backward rural areas of the developing countries (Sarma and Bhattacharyya, 2015; lyengar et al., 2009). Several indicators of health status show that India is still lagging behind the global standard. It has sometimes been argued that the lacklustre performance of India in terms of health is mainly because of poor health facilities, especially at the primary level (Ghosh and Mistri, 2016; Sarma and Bhattacharyya, 2015; Hati \& Majumder, 2011). Health facilities in general and hospitals in particular are facing different challenges related to their location, demand area, services and population pressure (Murad, 2007). People belonging to resource poor region are destined to face obstacles on their emergency as they have neither the money, nor the necessary facilities and incentives to access the outlying quality of care (Mamdani \& Bangser, 2004). Pregnancy induced complication and childbirth remain major challenges to the healthcare planner, provider and policy makers in the developing part of the societies (Goland et al., 2012), and India is no exception. Most remote areas of India suffer from high maternal mortality rates (MMR) and infant mortality rates (IMR) (Bhattacharyya, 2016; Ghosh and Mistri, 2016; Sarma and Bhattacharyya, 2015). Tables 1 and 2 illustrate the state of India's MMR and IMR.

Community differences in access to health facilities, the scantiness of healthcare providers and insufficient transport facilities play crucial roles for the insolvency in maternal health care system of the rural areas. Public health centres, located in the remote rural areas have been facing an acute shortage of skilled providers. The high death rate among pregnant women in the developing country is caused by the socialeconomical-cultural deprivation together with inefficient health care facilities (Bhattacharyya, 2016; Sarma and Bhattacharyya, 2015; Gottlieb, P. \& Lindmark, G., 2002). Skewed distribution of trained health personnel and their maximum engagement in routine duties that can be done by lesser qualified personnel are one of the problems in healthcare system, alleged by Bhore Committee, 1946 and Srivastava Committee, 1975 (Purohit \& Siddiqui, 1994). As a result, delay in care seeking for obstetric complications sometimes lead to maternal mortality as well as morbidity. Apart from insufficient manpower and socio-economic obligations, distance is the "crucial" dimension behind the utilisation of Maternal Health Care Services (Gage et al., 2006: 271). In many cases, the isolated outskirt locations of the healthcare facility, making it inaccessible mostly for the deprived poverty prone rural women (Mavalankaret al., 2009). Access to healthcare is a multi-dimensional system, including the factors like- availability and acceptability (financial and geographical) (Blanford et al., 2012; Taiar et al., 2010). Proximity to the service and protecting health is the key concern for the issue of health care service system; it is to correct the "health impairments" (Akhtar \& Izhar, 2010; Bhattacharyya, 2016; Ghosh and Mistri, 2016).The nature and type of terrain, road condition, location and distance of the health care centres are having greater influence to measure the degree and status of maternal healthcare services of a given area (Buor, 2002; Thaddeus \& Maine, 1994; Ghosh and Mistri, 2016).Accessibility of the healthcare facilities are concerned with the ability of a population to obtain a certain set of healthcare services, which according to Penchansky \& Thomas (1981) and Oliver \& Mossialos (2004) can be clubbed into three categories -(a) availability, (b) affordability and (c) geography (cited in 
Black et al., nd.). Deteriorating roads coupled with inadequate, unaffordable transport make it impossible for the poor to access the health facilities (Mamdani \& Bangser, 2004). In the case of women giving birth in the institution, they receive the Janani Suraksha Yojona (JSY) payment, in contrast to those who give birth at home. Study of Sourav Neogi in Sunderban region, has reported that difficult terrain, broken chain of transportation, especially in the least accessible island; force the women to deliver at home. Expenditure regarding drugs, consultancy fees and others increase the amount of "Out of Pocket Cost (OOP)" (Satia et al., 2014:28). These in many cases play as obstacles behind utilisation of MHCSs. Rumsey (2002) mentioned that lack of access to health care facilities refers not only to economic and socio-cultural distance but also to the physical distance (cited in Lalmalsawmzauva \& Nayak; nd).

\section{Table 1: State wise Maternal Mortality Ratio, India during Eleventh Plan, 2007-2012}

\begin{tabular}{cccc} 
India \& Major States & $\begin{array}{c}\text { MMR 1998 (Per } \\
\mathbf{1 0 0 0 0 0 ~ l i v e ~} \\
\text { births) }\end{array}$ & $\begin{array}{c}\text { MMR 2001-03 } \\
\text { (per 100000 live } \\
\text { births) }\end{array}$ & $\begin{array}{c}\text { Eleventh Five } \\
\text { Year Plan Goal ( } \\
\text { per 100000 live } \\
\text { births) }\end{array}$ \\
\hline India & $\mathbf{4 0 7}$ & $\mathbf{3 0 1}$ & $\mathbf{1 0 0}$ \\
\hline Assam & 409 & 490 & 163 \\
\hline Bihar/Jharkhand & 452 & 371 & 123 \\
\hline Madhya Pradesh/Chhattisgarh & 498 & 379 & 126 \\
\hline Orissa & 367 & 358 & 119 \\
\hline Rajasthan & 670 & 445 & 148 \\
\hline Uttar Pradesh/Uttarakhand & 707 & 517 & 172 \\
\hline Andhra Pradesh & 159 & 195 & 65 \\
\hline Karnataka & 195 & 228 & 37 \\
\hline Kerala & 198 & 110 & 45 \\
\hline Tamil Nadu & 79 & 134 & 57 \\
\hline Gujarat & 28 & 172 & 54 \\
\hline Haryana & 103 & 162 & 50 \\
\hline Maharashtra & 135 & 149 & $\mathbf{6 4}$
\end{tabular}

\section{Source: Government of India}

The inadequate transport facilities are reported to be major problems behind obstructed childbirth at hospitals. The locals of Birbhum villages, situated in West Bengal continue to suffer from the aforesaid problems, which bears reflections on their maternal health care service utilisation and pregnancy outcome (Bhattacharyya, 2016d; Sarma and Bhattacharyya, 2015g; Rana et al, 2015). Delivery complications vary from a low of 57 percent in Nadia to a high of 88.1 percent in
Birbhum district (DLHS-3, 2010). The proportion of women who had received full ANC was the highest in Haora (53.1\%) district and lowest was 24.8 percent in the Birbhum District (DLHS-4, 2014).The recent data on hospital information system of Department of Health and Family Welfare, Government of West Bengal shows that nearly four per cent of the total population in West Bengal is admitted in hospital during the period January 2009 to December 2009. If we name this patient admission percentage as 
the Critical Morbidity Percentage then that seems to be highest in Bankura with around 7 per cent followed by Nadia, Darjeeling, Birbhum (Hati \& Majumder, 2011).In order to reduce $\mathrm{MMR}$ and improve maternal health women need access to effective interventions and high-quality reproductive health care. Many countries have implemented programmes to expand access to interventions in order to reduce the level of unmet need for contraception, provide antenatal care during pregnancy and ensure delivery by a skilled birth attendant (World Health Organisation, 2011; see also, Bhattacharyya, 2016; Ghosh and Mistri, 2016; Sarma and Bhattacharyya, 2015).

\section{Table-2: Annual estimates of Infant mortality rate by sex, India and bigger States, 2008-2013}

\begin{tabular}{|c|c|c|c|c|c|c|c|c|c|c|c|c|c|c|c|c|c|c|}
\hline \multirow{2}{*}{$\begin{array}{c}\text { India\& } \\
\text { Bigger } \\
\text { States }\end{array}$} & \multicolumn{6}{|c|}{ Total } & \multicolumn{6}{|c|}{ Male } & \multicolumn{6}{|c|}{ Female } \\
\hline & 2008 & 2009 & 2010 & 2011 & 2012 & 2013 & 2008 & 2009 & 2010 & 2011 & 2012 & 2013 & 2008 & 2009 & 2010 & 2011 & 2012 & 2013 \\
\hline India & 53 & 50 & 47 & 44 & 42 & 40 & 52 & 49 & 46 & 43 & 41 & 39 & 55 & 52 & 49 & 49 & 44 & 42 \\
\hline $\begin{array}{l}\text { Andhra } \\
\text { Pradesh }\end{array}$ & 52 & 49 & 46 & 43 & 41 & 39 & 51 & 48 & 44 & 40 & 40 & 39 & 54 & 50 & 47 & 47 & 43 & 40 \\
\hline Assam & 64 & 61 & 58 & 55 & 55 & 54 & 62 & 58 & 56 & 55 & 54 & 53 & 65 & 64 & 60 & 60 & 57 & 55 \\
\hline Bihar & 56 & 52 & 48 & 44 & 43 & 42 & 53 & 52 & 46 & 44 & 42 & 40 & 58 & 52 & 50 & 50 & 45 & 43 \\
\hline Chhattisgarh & 57 & 54 & 51 & 48 & 47 & 46 & 57 & 50 & 48 & 47 & 46 & 45 & 58 & 57 & 54 & 54 & 47 & 47 \\
\hline Delhi & 35 & 33 & 30 & 28 & 25 & 24 & 34 & 31 & 29 & 25 & 24 & 23 & 37 & 34 & 31 & 31 & 26 & 25 \\
\hline Gujarat & 50 & 48 & 44 & 41 & 38 & 36 & 49 & 47 & 41 & 39 & 36 & 35 & 51 & 48 & 47 & 47 & 39 & 37 \\
\hline Haryana & 54 & 51 & 48 & 44 & 42 & 41 & 51 & 48 & 46 & 41 & 41 & 40 & 57 & 53 & 49 & 49 & 44 & 42 \\
\hline $\begin{array}{c}\text { Himachal } \\
\text { Pradesh }\end{array}$ & 44 & 45 & 40 & 38 & 36 & 35 & 43 & 44 & 35 & 36 & 35 & 33 & 45 & 45 & 47 & 47 & 38 & 36 \\
\hline $\begin{array}{l}\text { Jammu } \\
\text { Kashmir }\end{array}$ & 49 & 45 & 43 & 41 & 39 & 37 & 48 & 41 & 41 & 40 & 38 & 36 & 51 & 52 & 46 & 45 & 40 & 38 \\
\hline Jharkhand & 46 & 44 & 42 & 39 & 38 & 37 & 45 & 42 & 41 & 36 & 36 & 35 & 48 & 46 & 44 & 44 & 39 & 38 \\
\hline Karnataka & 45 & 41 & 38 & 35 & 32 & 31 & 44 & 41 & 37 & 34 & 30 & 30 & 46 & 43 & 39 & 39 & 34 & 32 \\
\hline Kerala & 12 & 12 & 13 & 12 & 12 & 12 & 10 & 10 & 13 & 11 & 10 & 10 & 13 & 13 & 14 & 14 & 13 & 13 \\
\hline $\begin{array}{l}\text { Maddhya } \\
\text { Pradesh }\end{array}$ & 70 & 67 & 62 & 59 & 56 & 54 & 68 & 66 & 62 & 57 & 54 & 52 & 72 & 68 & 63 & 63 & 59 & 55 \\
\hline Maharastra & 33 & 31 & 28 & 25 & 25 & 24 & 33 & 28 & 27 & 24 & 24 & 23 & 33 & 33 & 29 & 29 & 26 & 25 \\
\hline Odisha & 69 & 65 & 61 & 57 & 53 & 51 & 68 & 65 & 60 & 55 & 52 & 50 & 70 & 66 & 61 & 61 & 54 & 52 \\
\hline Punjab & 41 & 38 & 34 & 30 & 28 & 26 & 39 & 37 & 33 & 28 & 27 & 25 & 43 & 39 & 35 & 35 & 29 & 27 \\
\hline Rajasthan & 63 & 59 & 55 & 52 & 49 & 47 & 60 & 58 & 52 & 50 & 47 & 45 & 65 & 61 & 57 & 57 & 51 & 49 \\
\hline Tamilnadu & 31 & 28 & 24 & 22 & 21 & 21 & 30 & 27 & 23 & 21 & 21 & 20 & 33 & 29 & 24 & 24 & 22 & 21 \\
\hline $\begin{array}{c}\text { Uttar } \\
\text { Pradesh }\end{array}$ & 67 & 63 & 61 & 57 & 53 & 50 & 64 & 62 & 58 & 55 & 52 & 49 & 70 & 65 & 63 & 63 & 55 & 52 \\
\hline $\begin{array}{c}\text { West } \\
\text { Bengal }\end{array}$ & 35 & 33 & 31 & 32 & 32 & 31 & 34 & 33 & 29 & 30 & 31 & 30 & 37 & 33 & 32 & 32 & 33 & 32 \\
\hline
\end{tabular}

Source: SRS Statistical Report,2013, *Data relates to undivided Andhra Pradesh (estimates for newly created states of Telengana are not available in the source documents)

\section{Objectives}

The objectives are set forth as follows.

- Quantifying the prevailing road accessibility and connectivity status of the study area.

- Identifying the status of inadequacy in the provision of Maternal Health Care Services (MHCSs) regarding manpower distribution in accordance with population pressure.

- Assessing the status in provision of specific MHCSs using Paucity Index.
- Detecting the scenario of obstacles in the provision of services through Obstacle Score, and

- Revealing the dominant factors that govern the system of provision, utilisation and obstacles behind the MHCSs.

\section{Hypotheses of the study}

To establish the core concept of the study that whether the utilisation of the MHCSs are being influenced by the prevailing road accessibility 
and connectivity or not, the following null hypotheses have been taken into consideration.

(i) $\mathrm{H}_{0}=$ Underserved Score or Service inadequacy score has no impact on the Paucity Index of utilisation of MHCSs.

$\mathrm{H}_{1}=$ Underserved Score or Service inadequacy score has positive impact on the increasing trend of Paucity Index on MHCSs utilisation.

(ii) $\mathrm{H}_{0}=$ Obstacle Score in provision of services has no impact on the Paucity Index of utilisation of MHCSs.

$\mathrm{H}_{2}=$ Obstacle Score in provision of services has positive impact on the increasing trend of Paucity Index on MHCSs utilisation.

(iii) $\mathrm{H}_{0}=$ Accessibility Index (AI) has no impact on the scenario of service inadequacy of MHCSs.

$\mathrm{H}_{3}=$ Accessibility Index (AI) has positive impact on the scenario of increasing service inadequacy of MHCSs.

(iv) $\mathrm{H}_{0}=$ Accessibility Index (AI) has no impact on the Paucity Index of MHCSs.

$\mathrm{H}_{4}=$ Accessibility Index (AI) has positive impact on the increasing Paucity Index of MHCSs.

(v) $\mathrm{H}_{0}=$ Accessibility Index (AI) has no impact on the Obstacle Score of MHCSs.

$\mathrm{H}_{5}=$ Accessibility Index (Al) has positive impact on the increasing Obstacle Score of MHCSs.

\section{Data sources and methods}

\section{Nature of the study}

This study has adopted an epidemiological approach to detect the problems of health and related issues, depending upon two major foundations, that is, (i) asking questions and (ii) making comparisons. Basically, it is an analytical epidemiological study, where the subject of interest is the individual within the population. It is also a cohort based cross-sectional or prevalence study, a simplest form of an observational study.

\section{Data sources}

The entire study has been conducted depending upon empirical observation. Primary data have been collected from field survey (Cohort specific) and the institutional data have been collected from 29 Sub-Centres (SCs), four Primary Heath Care Centres (PHCs) of the respective C.D. Block, Murarai-II. To conduct the study, the cohort or target population has been fixed with three major criteria, these are(i) women belonging to reproductive age group (15-49), (ii) cohort should be in their third trimester ( 27 to 40 weeks) of Antenatal period (ANC) to three months of Postnatal (PNC) period, and (iii) the cohorts must be taking the maternal health care services of those health care facility centres, situated in the study area. For identifying the underserved scenario of service provision, responses of the Antenatal Midwives (ANM) and Accredited Social Health Activists (ASHA) of each SCs and PHCs have been taken into consideration. For this purpose, information regarding the number of villages within SCs along with their populations has been recorded from each SCs. List and number of ASHAs and ANMs had been collected from Block Primary Health Care Centres (BPHC) at Paikar. The Obstacle Score in providing the services has been calculated from the response of the SCs and PHCs. For evaluating the Paucity Index in utilisation of the MHCSs, responses had been taken from the cohort (married women belonging to reproductive age group and in conjugal relationship), from those who were present during the survey. 278 cohorts, who matched the selected principle and belonged to the respective block, had been interviewed with a pre-designed semi-structured questionnaire to establish the study. Here, the cohorts were clustered into two major groups- (a) Cohorts in their third trimester (ANC), and (b) Cohorts that belonged to postnatal stage.

\section{Methods}

(i) The scenario of inadequacy in the overall provision of MHCSs were identified through Underserved Scoring Index, (ii) The status of utilisation of MHCSs were then analysed using 
Paucity Index, (iii) Obstacles in the provision of MHCSs were detected through Obstacle Score, (iv) Several types of connectivity index, in which each index has its own applicable meaning were developed in the domain of transportation geography: Alpha, Beta, Gamma Index, and Shimbel Index; especially, it is known that Alpha index and Gamma index measure, the most fundamental properties of a network. One of the most important measures of connectivity of a network is the Alpha Index ( $\alpha$ ). It is adjusted from cyclomatic number $(\mu)$. It can be defined as the ratio of the observed number of fundamental circuits to the maximum number of circuits, which may exist in the system. The value of Alpha index would vary from 0 to 1 . The value ' 0 ' would mean a minimal connected network, whereas a value of ' 1 ' would refer to a maximally connected network (Raza \& Agarwal, 1999). It is a measure of connectivity, which evaluates the number of cycles in a graph in comparison with maximum number cycles. The higher the index, the greater is the degree of connectivity in the network (Saxena, 2012). Beta Index ( $\beta$ ) measures the level of connectivity in a network and is expressed by the relationship between the numbers of links $(e)$ over the number of nodes $(v)$. For tree and simple networks, $\beta<1$ and for a connected network with one cycle, $\beta=1$. More complex network has a value greater than 1 . The connectivity as measured by Gamma Index $(\gamma)$ varies from a set of nodes having no interconnection to the one in which every node has an edge connected to other nodes in the graph. The numerical range of the index is 0 to 1 . The Cyclomatic number is a different way of measuring connectivity. In a disconnected tree type network the index is to be ' 0 '. Here, the number 2 indicates low to moderate connectivity status (Lee \& Chi, nd). Unlike these four fundamental indices, Shimbel Index, $D(G)$ is a summation of all the shortest path distances among all points (vertex and node) in a defined zone or a circuit (Lee \& Chi, nd).
To extract factors from the data sets, the Principal Components Analysis (PCA) method, the most common form of factor analysis has been chosen. The criteria considered to determine the number of factors to be retained for further analysis was suggested by Harman in 1976 (Hirama et al., 2010). The PCA is a procedure to convert a set of observations of possibly correlated variables into a set of values of linearly uncorrelated variables called principal components (Kothari \& Garg, 2014).

The statistical analyses have been performed using Microsoft Office Excel, 2007 and SPSS, Version 15 (SPSS Inc., Chicago, Illinois, USA, 2009) and spatial distributions have been mapped through Arc GIS, Version 9.3 (Environmental Systems Research Institute, Esri Developers Summit, 2008). The significance levels between the road network and provision of MHCSs have been tested through Student tTest and $p$-value.

\section{Study Area}

The C. D. Block Murarai-II lies in the northern part of the Birbhum District, West Bengal, with an extension from $24020^{\prime} 33^{\prime \prime} \mathrm{N}$ to $24033^{\prime} 35^{\prime \prime}$ $\mathrm{N}$ and $87050^{\prime} 41^{\prime \prime} \mathrm{E}$ to $87058^{\prime} 35^{\prime \prime} \mathrm{E}$ (Figure 1 ) . The Block is located at a distance of $95 \mathrm{kms}$ from District Headquarter, that is, Suri. It is bounded on the North by C. D. Block Murarai-I and District Murshidabad, on the East by District Murshidabad entirely, on the West by C. D. Block Murarai-I, and on the South by the Nalhati, police station (District Statistical Handbook, Birbhum, 2011; Population Census, Govt. of India, 2011).The Block is highly populated amongst 19 other Blocks of the district with 239770 populations (Report from SCs, 2015-'16). The population density of the study area is $1143 / \mathrm{sq} . \mathrm{km}$, more than the district's, 707.60/sq.km, comprising an area about 185.33 sq.km (Population Census, 2011). There are nine Gram Panchayats (GPs) and 65 Mouzas in the study area, getting the service of 29 SCs, four PHCs and one BPHC, which is situated in Paikar-I G.P. 


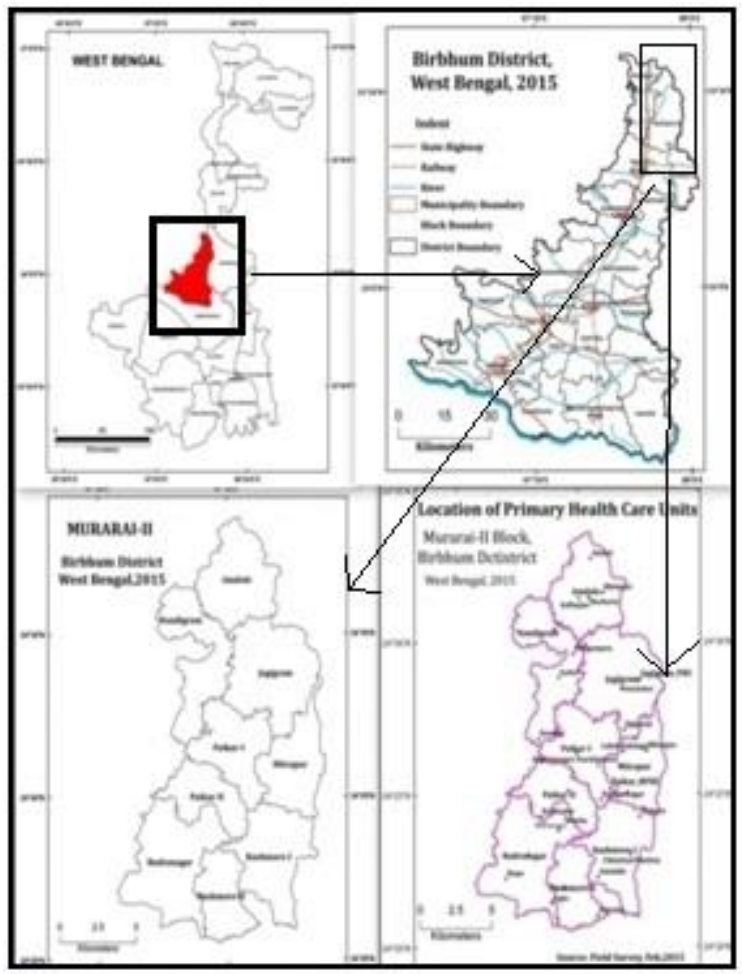

Figure 1: Location Map (Source: GPS points

of the field survey, 2015; CMOH office, 2015),

taken during field survey, 2015)

\section{Results and Discussion}

\section{Prevailing road network accessibility and connectivity status}

Convenience to avail the healthcare facility centres is a highly indispensable factor to control the utilisation of MHCS, as in most cases pregnant women, belonging to resource poor regions, often suffered from delivery related complication because of less and timely access to transport to reach the facility centre. Service proximity can be measured by the connectivity and accessibility status of the study area. One of the most important measures of connectivity of a network is the Alpha Index ( $\alpha$ ) (Table 3).

Higher the index, the greater is the degree of connectivity in the network. Here, the index value, 0.15 signals a very low degree of connectivity. The complexity and simplicity status are being reflected by the Beta Index ( $\beta$ ), which represents a complicated network structure with value 1.11. Gamma Index $(\gamma)$, the measure of connectivity, which considers the relationship between the numbers of observed links and the numbers of possible links. Here, the value 0.48 indicates lower connectivity, which means that the number of noninterconnected set of nodes are greater than which have an edge connected to another node in the circuit (Table 3 ). Most of the roads here are not connected apart from the two major Pradhan Mantri Gram Sadak Yojana (PMGSY) roads passing through Hiyatnagar - one is Hiyatnagar to Kushmore-II and the second is Hiyatnagar to Bisore via Mitrapur and Sadasibpur. There are three PMGSY roads in the C.D.Block. All of them pass through Hiyatnagar.

From the Shimbel Index value, it is evident that the most accessible GPs are- Paikar-I (15) and II (16), which scores the higher Shimbel Index value, where Amdol and entire Kushmore-I are the outlying areas with sparse accessibility and shows a value of 25 and 31 respectively [Figure 2 (a)]. It is because of Hiyatnagar, which is located in Paikar-II G.P., the major junction point of the study area. Paikar Bustand (in Paikar-I) is the first place to arrive before reaching to any places of Murarai-I, Amdol and 
Nandigram. The Koning number describes the degree of centrality of any node of a network. Lowest is the number, the higher would be the centrality. In the study area, the Koning number is low in Paikar-II (3) and then in Paikar-I (4). On the other hand, the remote GPs of the block
are-Kushmore-I and Amdol with a Koning value of six for each. Nandigram, Jajigram and Kushmore-II each have $a=$ value of five and the values for rest of the GPs ranges in between four to five [Figure 2 (b)].

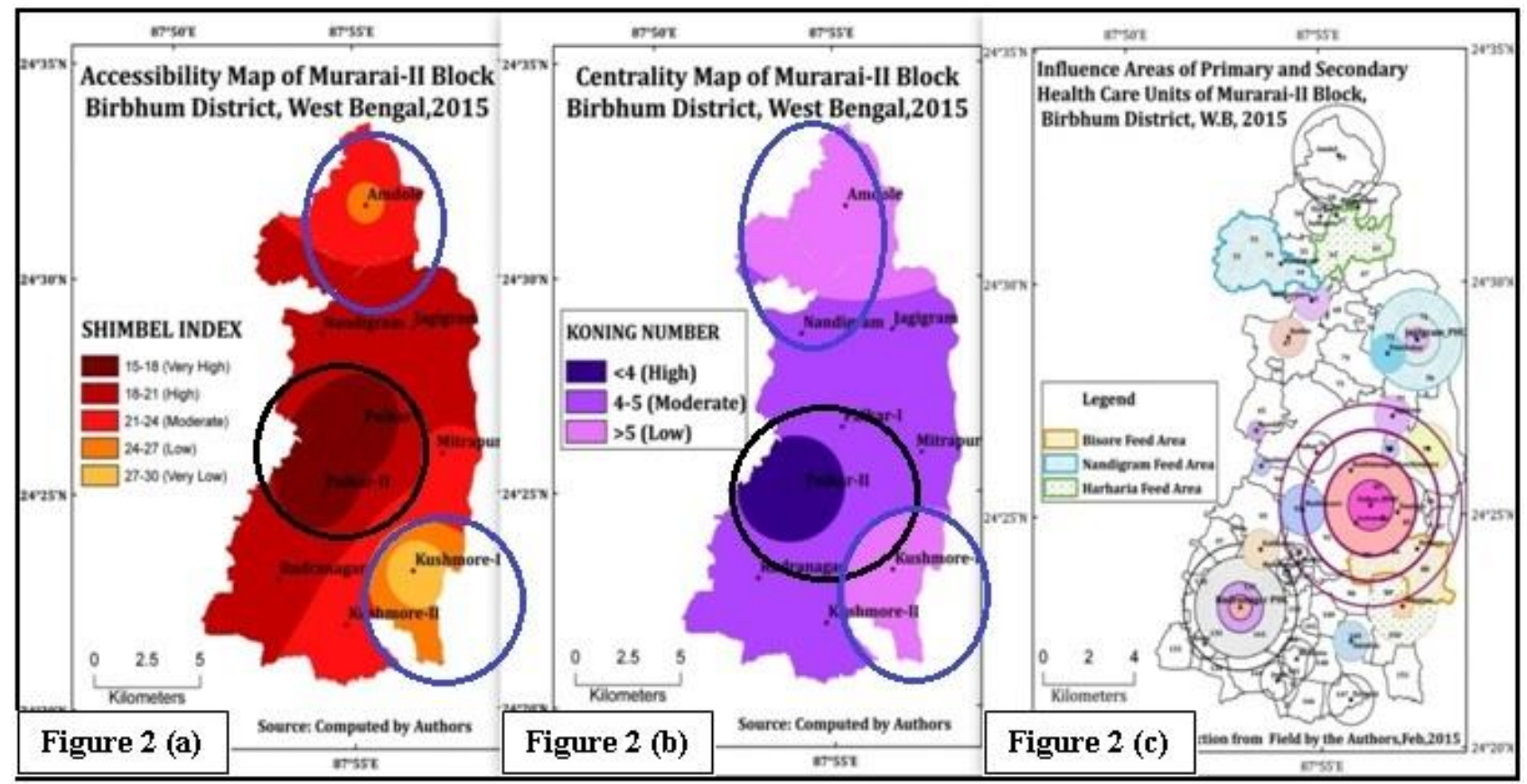

Figure 2: Modelling Accessibility and Connectivity Status Along with Influence Zone of Each Health Care Centres, Murarai-II C.D.Block, Birbhum District, West Bengal,2015

\section{Scenario of Inadequacy in Maternal Health Care Services}

The availability of health centres within three to five kms of the neighbourhood have a strong purport on the concentration of served and underserved population in the study area. It is evident that the influence zones of those SCs' are nearly small, which are situated far from the BPHC, like-Kushmore-I and II (Figure 2). According to the detailed guidelines issued by the Government of India (GOI) in a matter of selection and training of ASHA, one of the key strategies under the National Rural Health Mission (NRHM) of India is about having a Community Health Volunteer (ASHA) for every 1000 population in a village. At the same time, each province has been given the flexibility to relax the population norms (one ASHA for every 1000 population in a village). It means a village with large population share can be recruited with one ASHA for more than 1000 population. At the same time the educational qualifications of the ASHAs have been given elasticity on a case to case basis, depending on the local conditions as far as their recruitments are concerned (NRHM, 2014).In case of Murarai-II, one ASHA has been allotted for every 1200 population because of the excessive population pressure of the block (222033, Population Census, 2011). It is 7\% of the total population of Birbhum District. The population density of the concerned block is $1143 / \mathrm{km}^{2}$, which is again higher than the district's population density, $\left(707.60 / \mathrm{km}^{2}\right.$, Population Census, 2011).The underserved population concentration is high $(L Q=>1.2)$ in those areas rests in the last row of accessibility and connectivity index, likeKushmore-II, Amdol (Figure 3).A case of home delivery and still birth are usual pictures in backward rural settings, especially for those areas located far from the facility centre. Home delivery is a common scenario of Kushmore-I, especially in the rainy seasons (mention the months here). A woman from Dhaboparavillage had to experience stillbirth. It was a case of 
breech birth, that is, when a baby is born bottom first (or feet first) position instead of the head. Seeing the severity of delivery and the pain the village Dai (mid-wife) advised her to be taken to the hospital. Despite repetitive calls to the Nischoy Jan/Matriyan, none of them had arrived to take this lady to the Rampurhat hospital (which is almost $40 \mathrm{Kms}$ from the village). Because of excessive distance and bad road conditions, ambulances avoid these areas of Kushmore-I G.P. Besides, this lady belongs to a very poor family. Therefore, renting a private vehicle to the Rampurhat hospital was too expensive for them. As a fate, she had to deliver a dead baby in an entire unserved environment. This is not only the first case in Kushmore, but also most areas with bad roads and long distances from the main facility centres experiences cases vulnerable pregnancy outcomes on a regular basis.

Apart from these two areas, Paikar-II portrays the same value on the underserved population concentration status. This is because of excessive population pressure, as the area ranks third in the rank index of population density (more than $1600 / \mathrm{km}^{2}$ ). The maximum served population is getting concentrated nearer to the facility within one to three kms of radius.

\section{Table3: Methods, Parameters, Techniques and Results in Modelling the Road Network} and Connectivity Index, Murarai-II C.D. Block, BirbhumDistrict, West Bengal, 2015

\begin{tabular}{|c|c|c|c|}
\hline Methods & Parameters & Applied formulas & Result \\
\hline \multirow{7}{*}{$\begin{array}{l}\text { Road network } \\
\text { Analysis } \\
\text { (Accessibility and } \\
\text { Connectivity index) }\end{array}$} & Cyclomaticnumber $(\mu)$ & $(\mu)=(e-v+p)$ & 2 \\
\hline & Alpha index $(\alpha)$ & $\frac{\mu}{2 v-p}$ & 0.15 \\
\hline & Beta index $(\beta)$ & $\frac{e}{v}$ & 1.11 \\
\hline & Gamma index $(\gamma)$ & $\frac{e}{3(v-2)}$ & 0.48 \\
\hline & \multicolumn{2}{|c|}{$\begin{array}{l}\text { Where, } e=\text { No. of edges, } v=\text { No.of vertex } \\
p=\text { No. of sub-graphs (Source: Saxena, 2012) }\end{array}$} & \multirow[t]{2}{*}{$\begin{array}{c}\text { Source: } \\
\text { Computed by the } \\
\text { authors, } 2015 \\
\end{array}$} \\
\hline & \multicolumn{2}{|l|}{ Shimbel index, $D(G)$} & \\
\hline & \multicolumn{3}{|c|}{$\begin{array}{l}\text { Where, } D(G)=\text { Shimbel index, } d_{i j}=\text { Shortest path between } i \text { node to } j \\
\text { node (Source: Lee \&Chi,nd) }\end{array}$} \\
\hline
\end{tabular}

\section{Table 4: Accessibility and connectivity index, Murarai-Il C.D.Block, Birbhum District, 2015}

\begin{tabular}{ccccc} 
Category & Parameters & Maximum values & Minimum values & Average values \\
\hline Status of & Shimbel index & 31 & 15 & 21.11 \\
\cline { 2 - 5 } accessibility & Koning number & 6 & 3 & 4.78
\end{tabular}

Source: Computed by the Authors, 2015 


\section{Table 5: Methods and parameters used in modelling the inadequacy in provision of maternal} health care services, Murarai-II C.D.Block, Birbhum District, 2015
Method
Parameters
Sub-Parameters
Applied Formulas

\begin{tabular}{|c|c|c|}
\hline & $\begin{array}{l}\text { (a) } \\
\text { Concentration } \\
\text { index of }\end{array}$ & $\begin{array}{l}\text { (i) Total population under the official } \\
\text { (by the BPHC) influence zone of each } \\
\text { SC }\end{array}$ \\
\hline & $\begin{array}{l}\text { underserved } \\
\text { population }\end{array}$ & $\begin{array}{l}\text { (ii) Number of Accredited Social } \\
\text { Health Activist (ASHA) being } \\
\text { sanctioned to each respective SCs. }\end{array}$ \\
\hline & & (i) Total underserved population of \\
\hline & $\begin{array}{l}\text { population } \\
\text { density }\end{array}$ & (ii) Area $\left(\mathrm{km}^{2}\right)$ of respective G.P. \\
\hline & $\begin{array}{l}\text { (c) } \\
\text { Concentration } \\
\text { index of }\end{array}$ & $\begin{array}{l}\text { (i) Total number of villages under the } \\
\text { authoritative influence zone of each } \\
\text { SC }\end{array}$ \\
\hline Underserved & $\begin{array}{l}\text { villages } \\
\text { without ASHA }\end{array}$ & $\begin{array}{l}\text { (ii) Number of ASHA being } \\
\text { sanctioned to each respective SC }\end{array}$ \\
\hline & & (iii) Number of villages without ASHA. \\
\hline & $\begin{array}{l}\text { (d) } \\
\text { Underserved } \\
\text { scoring index }\end{array}$ & $\begin{array}{l}\mathrm{X}_{1-} \text { Percentage of underserved } \\
\text { population to total population of the } \\
\text { G.P. }\end{array}$ \\
\hline & & $\begin{array}{l}\mathrm{X}_{2} \text {-Percentage of villages without } \\
\text { ASHA }\end{array}$ \\
\hline & & $\begin{array}{l}X_{3} \text {-Percentage of half part served } \\
\text { villages }\end{array}$ \\
\hline & & $\begin{array}{l}\mathrm{X}_{4} \text {-Percentage of villages situating } \\
\text { beyond two kms from each SC }\end{array}$ \\
\hline & & $\begin{array}{l}\mathrm{X}_{5} \text {-Percentage of population have to } \\
\text { travel more than two kms to reach } \\
\text { the SC }\end{array}$ \\
\hline
\end{tabular}

(Source: Mahmood, 2002, Sarkar, 2013)

Interrelationship between the parameters of underserved score of maternal health care services and extraction of dominant factor in the system

From the correlation matrix, it is evident that population living beyond two kms of serve zone of each SCs is considerably influencing the scenario of inadequacy in the provision of MHCSs in the Murarai-II Block (Table 6 and 7). It significantly shows high correlation with the parameters -villages without ASHAs and villages beyond two kms serve zone of each SC, (a) Standard Score (Z-

Score) of Each Parameter

$=\frac{\left(x_{i}-\mu\right)}{\sigma}$ Equation (1)

Where, $x_{i}=$ Individual Item $\mu=$ Mean of the Population $\sigma=$ Standard Deviation of the Population

(b) Composite Score (Summation of Each ZScore Value)

$=\frac{\left[\sum\left(x_{i}-\mu\right)\right]}{\sigma}$....Equation (2) 
number of ASHAs, especially in those areas kms of distance to access the facility (Table 7). where people have to cover more than two

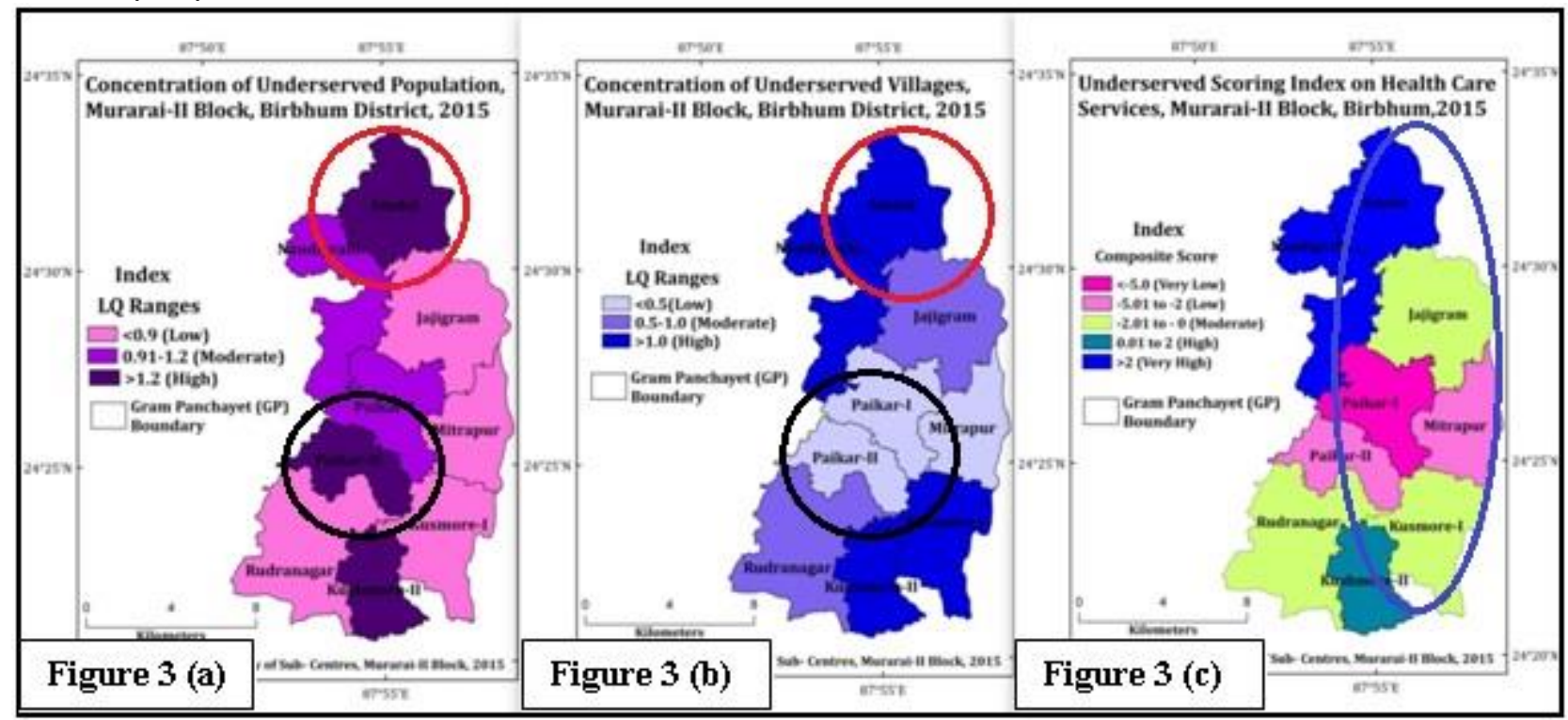

Figure 3: Scenario of Inadequacy in Maternal Health Care Services, Murarai-IIC.D.Block, Birbhum District, West Bengal, 2015

Table 6: Factors Dominating the Underserved Score of Maternal Health Care Services (Pearsonian Product Moment Correlation Matrix), Murarai-IIC.D.Block, BirbhumDistrict, 2015

\begin{tabular}{cccccc} 
Parameters & $X_{1}$ & $X_{2}$ & $X_{3}$ & $X_{4}$ & $X_{5}$ \\
\hline$X_{1}$ & 1 & 0.50 & 0.16 & -0.22 & -0.02 \\
\hline$X_{2}$ & 1 & 0.54 & 0.61 & $0.75^{*}$ \\
\hline$X_{3}$ & & 1 & 0.45 & 0.38 \\
\hline$X_{4}$ & & 1 & $0.94^{* *}$ \\
\hline$X_{5}$ & & & 1 \\
Note: Correlation is significant at the $\mathbf{0 . 0 5}$ level (2-tailed) & \\
$* *$ Correlation is significant at the $\mathbf{0 . 0 1}$ level (2-tailed) &
\end{tabular}

Table 7: Factors Dominating the Underserved Score of Maternal Health Care Services (Extraction of Principal Components with Cumulative Percentages of Variance), Murarai-IIC.D.Block, BirbhumDistrict, 2015

\begin{tabular}{cccccc}
$\begin{array}{l}\text { PCA } \\
\text { (Variance explained) }\end{array}$ & $\mathrm{X}_{1}$ & $\mathrm{X}_{2}$ & $\mathrm{X}_{3}$ & $\mathrm{X}_{4}$ & $\mathrm{X}_{5}$ \\
\hline Parameters & & & & & \\
\hline PC-1 (57.84 \%) & 0.18 & 0.89 & 0.66 & 0.88 & 0.92 \\
\hline PC-2 (26.63\%) & 0.95 & 0.37 & 0.18 & -0.44 & -0.25
\end{tabular}

Inadequate Provision of Specific Maternal Health Care Services: Paucity Index

The association between cohorts and factors behind the utilisation of maternal health care services covering three main aspects of maternal health status-these are- use of antenatal care during second trimester, during third trimester and use of postnatal care in the 42 days post-partum period. Different variables have been considered for identifying the Paucity Index in utilisation of MHCSs, which are- percentages of cohort, which belongs to 
the three broad clusters mentioned previously maternal health care service is becoming a (Table 8). The meagreness in the utilisation of factual depiction from the Paucity index.

Table 8: Methods and Parameters used in Modelling the Inadequate Utilisation of Maternal Health Care Services (Paucity index), Murarai-II C.D.Block, Birbhum District, 2015

\begin{tabular}{|c|c|c|}
\hline Method & Parameters & Applied formulas \\
\hline \multirow{10}{*}{$\begin{array}{l}\text { Paucity index } \\
\text { in utilisation } \\
\text { of maternal } \\
\text { health care } \\
\text { service }\end{array}$} & $\mathrm{P}_{1}$-Inadequate Tetanus Toxide (TT) & \multirow{10}{*}{$\begin{array}{l}\text { (a) Proportional weighting method } \\
\text { (i) Sample fraction }(f)=\frac{n}{N} \ldots \ldots . . \text { Equation } \\
\text { (1) } \\
\text { Where, } n=\text { Response rate as "yes" for } \\
\text { each item, } N=\text { Total no. of sample }\end{array}$} \\
\hline & $\mathrm{P}_{2}$-Insufficient Iron Folic Acid (IFA) & \\
\hline & $P_{3}$-Inadequate check-ups & \\
\hline & $\begin{array}{l}\mathrm{P}_{4} \text {-Did not get registered within first } \\
\text { trimester }\end{array}$ & \\
\hline & $\begin{array}{l}P_{5} \text {-Don't have registration till the time } \\
\text { of survey }\end{array}$ & \\
\hline & $\begin{array}{l}\mathrm{P}_{6} \text {-Percentage of PNC with } \\
\text { institutional delivery but without } \\
\text { getting accompanied by ASHA }\end{array}$ & \\
\hline & $\begin{array}{l}P_{7} \text {-Percentage of PNC with less than } \\
\text { three PNC visit }\end{array}$ & \\
\hline & $\begin{array}{l}\mathrm{P}_{8} \text {-Percentage of PNC never been } \\
\text { visited by an ASHA }\end{array}$ & \\
\hline & $\begin{array}{l}\text { P9-Percentage of Low Birth weight } \\
\text { (LBW) cases not being managed by } \\
\text { facility }\end{array}$ & \\
\hline & $\begin{array}{l}\text { P10-Percentage of PNC (JSY } \\
\text { beneficiary) without any financial } \\
\text { assistance for the institutional } \\
\text { delivery. }\end{array}$ & \\
\hline
\end{tabular}

(Source: Diop, et. al. 2009 and Sarraf\& Chen, 2007)

The use of maternal health care service remains low in Amdol G.P. followed by Mitrapur and Kushmore-I. Thus they are showing high paucity index (>4) within the Murarai-II Block, in comparison to other G.Ps. For example, the analysis revealed that almost $76.7 \%$ of the cohorts have recorded within adequate TT, $55.8 \%$ with inadequate IFA, $67.44 \%$ with inadequate check-up and $66.67 \%$ PNC mothers are with less than three PNC visit by health workers (ASHAs and ANMs). The scenario is more or less the same in Kushmore-I and Mitrapur. Almost all the SCs of Mitrapur GP are lying at a distance of more than $10 \mathrm{kms}$ from the Paikar BPHC. Some of the mouzas of these

two-gram panchayats are located
comparatively at a greater distance from the BPHC, these are -Math Karamja $(11 \mathrm{kms}$ from the BPHC), Dantura and Mitrapur (10 kms. from the $\mathrm{BPHC}$ ). The situation is even worse in Kushmore-I G.P. Here, the average distance of mouzas from the BPHC is $14.25 \mathrm{kms}$, where 50 $\%$ of the mouzas are located at a distance of 16 to $18 \mathrm{kms}$ from the BPHC, these are-Chhatina, Amuddya, Raghurpukur, Sahabiroli and Kalikapur. People belonging to these regions are often being deprived from the awareness programmes conducted by the BPHC. Apart from this, the locals of these areas suffer from service ambiguity and manpower insufficiency. 


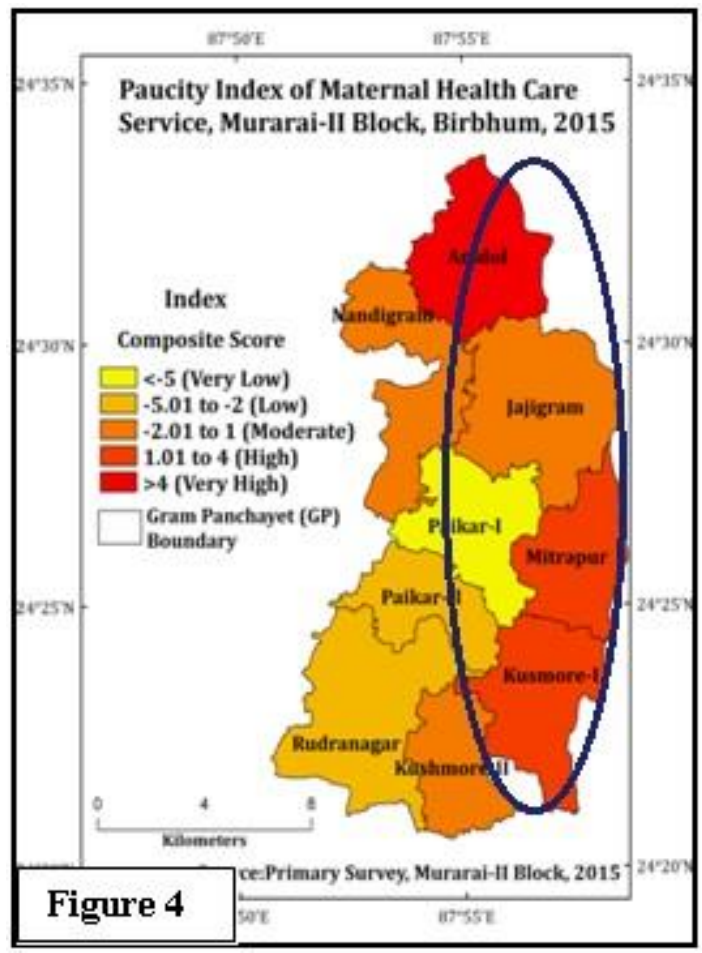

For example: frequent transfer of ANMs, shortage in manpower. Amdol, and Kushmore-I and II are the most victimised G.Ps. suffer from various fatal consequences related to obstetric outcomes. For examples, imprudent management of low birth weight cases, insufficient PNC visits by health workers and lack of surveillance in providing financial assistance to the PNC mothers, lack of institutional delivery, and apathetic behaviour of the health care providers.

\section{Interrelationship between the Parameters of Paucity Index of Maternal Health Care Services Utilisation and Extraction of Dominant Factor in the System}

From the multivariate correlation matrix, it is evident that there is a strong positive and significant relationship (0.84) between $\mathrm{P}_{7}$ and $P_{10}$ (Table 9). The next significant relationship (0.77) could be seen between $P_{6}$ and $P_{8}$ (Table 9). Hence, the picture is clear that utilisation of MHCSs is inadequate in the region and decrease when a woman succeeds to her postpartum stage. The paucity index in utilisation and provision of MHCSs are affected mostly by the ambiguity in postnatal care (Tables 9 and 10).

\section{Quadrant Comparison between Underserved Score and Paucity Index of Maternal Health Care Services Provision}

Paikar-I and II are located in the -, + co-ordinate in both the quadrant distribution analysis (Figures 5 and 6). This means the dominant factors of first PCA are working positively in these two blocks and negating the underserved scenario and paucity index in MHCSs utilisation. Amdol and Nandigram on the other hand are stuck with their,++ position in both the quadrant distribution (Figures 5 and 6). Here, it can be explained that the dominant factors of the first PCA play a very crucial but dominant role in both the underserved MHCSs scenario and the paucity index in the utilisation of MHCSs. The major factors for underserved scoring indices are-villages without ASHAs; villages beyond two kms serve zone of each SC, population living beyond two kms serve zone of the SC. Whereas, percentage of PNC (with institutional delivery) without getting accompanied by ASHA and percentage of PNC never ever been visited by ASHA are the prime factors for the paucity index. There is a complete shift in position for Jajigram and Kushmore-II in two-quadrant distribution. For Jajigram, it was lying in + , - position in the first quadrant and has been shifted in the second quadrant to,++ co-ordinate. It indicates that 
the villages and population beyond two kms

behind the underserved situation of Jajigram.

feed zone of SC and play as influential factors

Table 9: Factors Dominating the Paucity Index of Maternal Health Care Services Utilisation (Pearsonian Product Moment Correlation Matrix), Murarai-IIC.D.Block, BirbhumDistrict,2015

\begin{tabular}{|c|c|c|c|c|c|c|c|c|c|c|}
\hline Parameters & $\mathrm{P}_{1}$ & $\mathrm{P}_{2}$ & $P_{3}$ & $\mathrm{P}_{4}$ & $P_{5}$ & $\mathrm{P}_{6}$ & $\mathrm{P}_{7}$ & $\mathrm{P}_{8}$ & $\mathrm{P}_{9}$ & $P_{10}$ \\
\hline $\mathrm{P}_{1}$ & 1 & 0.32 & 0.63 & 0.47 & 0.11 & 0.12 & 0.13 & 0.28 & 0.45 & 0.02 \\
\hline $\mathrm{P}_{2}$ & & 1 & 0.01 & 0.58 & -0.05 & $0.72 *$ & 0.27 & $0.71^{*}$ & 0.01 & 0.14 \\
\hline$P_{3}$ & & & 1 & -0.17 & 0.01 & -0.14 & -0.14 & -0.11 & 0.50 & -0.44 \\
\hline $\mathrm{P}_{4}$ & & & & 1 & 0.23 & 0.35 & 0.25 & 0.18 & -0.15 & 0.46 \\
\hline $\mathrm{P}_{5}$ & & & & & 1 & -0.52 & $-0.72 *$ & -0.43 & -0.48 & -0.56 \\
\hline$P_{6}$ & & & & & & 1 & 0.45 & $0.77^{*}$ & 0.02 & 0.42 \\
\hline$P_{7}$ & & & & & & & 1 & 0.48 & 0.43 & $0.84 * *$ \\
\hline$P_{8}$ & & & & & & & & 1 & 0.27 & 0.28 \\
\hline $\mathrm{P}_{9}$ & & & & & & & & & 1 & 0.25 \\
\hline$P_{10}$ & & & & & & & & & & 1 \\
\hline
\end{tabular}

Table 10: Factors Dominating the Paucity Index of Maternal Health Care Services Utilisation (Extraction of Principal Components with Cumulative Percentages of Variance), MuraraiIIC.D.Block, BirbhumDistrict, 2015

PCA

\begin{tabular}{ccccccccccc}
$\begin{array}{c}\text { (Variance } \\
\text { explained) }\end{array}$ & $\mathrm{P}_{1}$ & $\mathrm{P}_{2}$ & $\mathrm{P}_{3}$ & $\mathrm{P}_{4}$ & $\mathrm{P}_{5}$ & $\mathrm{P}_{6}$ & $\mathrm{P}_{7}$ & $\mathrm{P}_{8}$ & $\mathrm{P}_{9}$ & $\mathrm{P}_{10}$ \\
\hline $\begin{array}{c}\mathrm{PC}-1(36.02 \\
\text { \%) }\end{array}$ & 0.32 & 0.70 & -0.15 & 0.53 & -0.58 & 0.86 & 0.77 & 0.78 & -0.41 & 0.31 \\
\hline $\begin{array}{c}\mathrm{PC}-2(21.08 \\
\text { \%) }\end{array}$ & 0.12 & -0.35 & 0.46 & -0.56 & -0.62 & -0.21 & 0.43 & 0.05 & 0.66 & 0.78
\end{tabular}

The factors like- percentage of PNC (with These two are the most deprived villages of the institutional delivery) without being G.P., Jajigram. People visit Gaganpur by accompanied by ASHA and, percentage of PNC crossing the paddy field during emergence of with never ever been visited by ASHA are the any obstetric emergency. In the first quadrant prime factors for the paucity index of Jajigram. distribution, Kushmore-II is shares the coKichai, a village in Jajigram, neither have any ordinates with Amdol and Nandigram, which health worker within the village nor have a Dai explains the same, conditions conversely for (midwife) to assist the delivery. Out of the quadrant distribution of paucity index; it compulsion people to depend on a single Dai, shares the co-ordinate with Rudranagar. who lives in Gaganpur, another village of Because of close proximity of the Rudranagar Jajigram G.P., which is around five kms away SC, Kushmore-II is somewhere being benefitted from Kichai. People have to reach Gaganpur by by the surveillances of Rudranagar SC and crossing another village named, Barsapukur, Paikar BPHC. The postnatal check-ups and lying in between Kichai and Gaganpur. Due to antenatal service utilisation are getting a inadequate mode of transportation, walking is positive connotation for its situational the only way to reach the village, Gaganpur. perspective. 

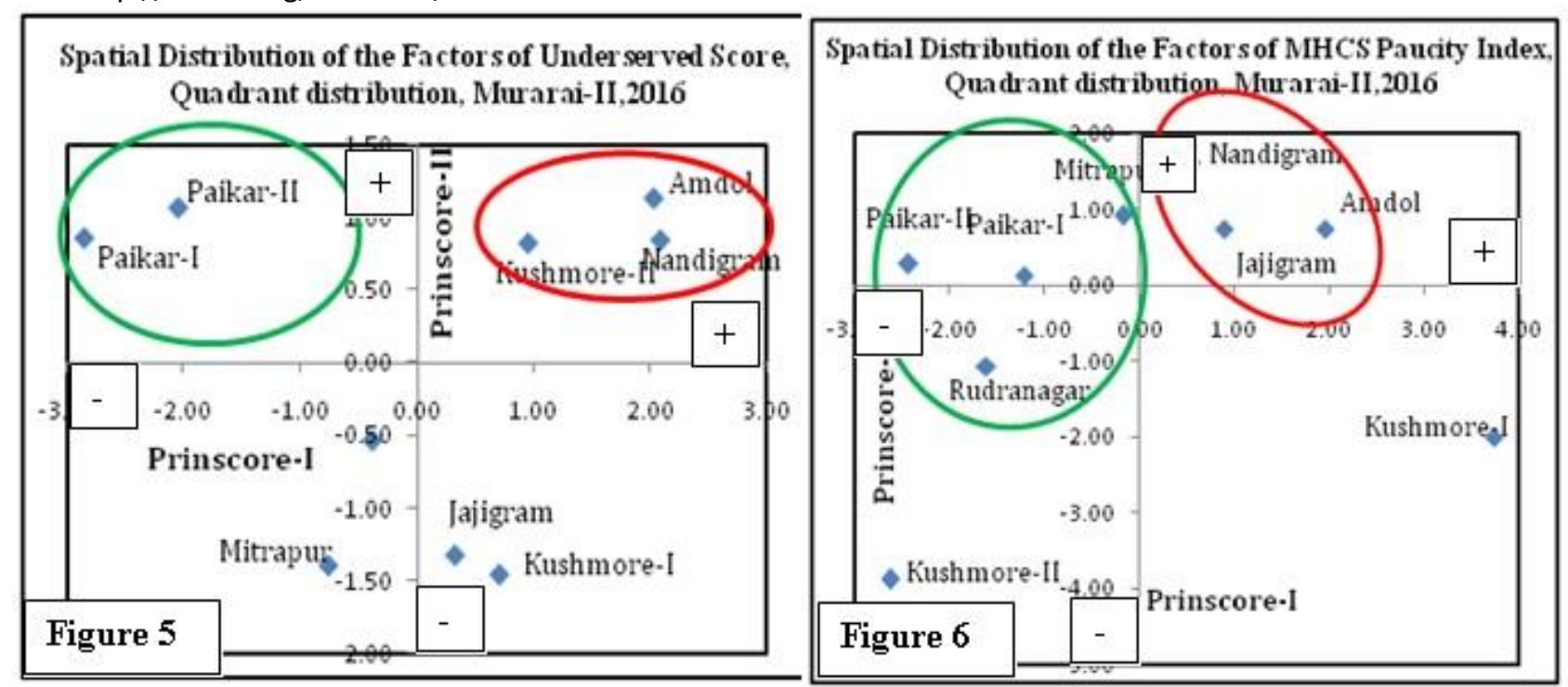

\section{Quadrant Comparison between Underserved Score and Paucity Index of Maternal Health Care} Services Provision

\section{Obstacles in Provision of Maternal Health Care Services}

Obstacles in provision of maternal health care services have been identified through obstacle score. It depicts the major difficulties on the way to provision and utilisation of maternal health care services. Obstacles seem to be high in Kushmore-I and II along with Amdol G.P. Except for population pressure, all the four parameters among the five (bad road communication, no mode of communication to the remote places, frequent transfer of the ANM, population pressure, inadequate man power) play major roles behind the high obstacle score of the said G.Ps (Table 11). Frequent transfer of ANM is a common scenario for the SCs of Kushmore-I G.P. In a very recent past (September 2015), the field survey unfolds a surprising picture in the Kushmore-I G.P., regarding the transfer of ANMs. All the three SCs-Amuddya, Chhatina and Bisore have experienced transfer of ANM to the adjacent district of Murshidabad within six month tenure. All of them were first ANMs. According to the local people's view, people are not willing to work in such a remote place, devoid of sufficient transportation mode along with bad and rough roads. Long distance, availability of transport, cost of transportation, condition of the roads are the governing factors that work in the mind-set of the people to seeking care (Thaddeus \& Maine, 1994b; Gage \& Calixte, 2006a). SCs in the remote places or distant from the BPHCs are in a distress condition in the study area. The following two examples can be cited as the cases studies.

\section{Table 11: Methods and Parameters used in Modelling the Obstacles in Provision of} Maternal Health Care Services, Murarai-IIC.D.Block, Birbhum District, 2015

\begin{tabular}{|c|c|c|}
\hline Method & Parameters & Applied formulas \\
\hline \multirow{7}{*}{ Obstacle Score } & $\mathrm{O}_{1}$-Bad road communication & \multirow{7}{*}{$\begin{array}{l}\text { Proportional weighting method } \\
\text { Sample fraction }(f)=\frac{n}{N} \\
\text { Where, } n=\text { Response rate as "yes" } \\
\text { for each item, } N=\text { Total no. of } \\
\text { sample } \\
\text { Scale weight }(w)=\frac{1}{f} \\
\text { Summation of total scale Weight } \\
\text { score } \\
\text { SSources: Diop et al. (2009) and } \\
\text { Sarraf\& Chen, (2007)\} }\end{array}$} \\
\hline & & \\
\hline & $\begin{array}{l}\mathrm{O}_{2} \text {-Insufficient mode of communication to } \\
\text { the remote places, }\end{array}$ & \\
\hline & $\mathrm{O}_{3}$-Frequent transfer of the ANM & \\
\hline & $\mathrm{O}_{4}$-Excessive population pressure & \\
\hline & & \\
\hline & $\mathrm{O}_{5}$-Inadequate manpower. & \\
\hline
\end{tabular}




\section{Case I}

Bhimpur sub-centre (SC) and Bhimpur Primary health Care Centre (PHC), both located in Amdol G.P are $16 \mathrm{kms}$ away from Paikar BPHC. It was considered a hospital long time ago but now it works only as a sub-centre. Just the side of SC and now in a distress condition locates the PHC with no facility. According to the Anti Natal Midwives (ANMs) and Community Health Workers (CWG), doctors never come to the PHC and SC. Local people throw bottles after getting drunk by the side of the PHCs; even the electricity connection have been stolen from the SC. The ANM have seen snakes lying in the room several times, especially during monsoon. There is no separate clinic or examination room. In spite of repeated complaints to the BPHC and local Gram Panchayat, no measures have yet been taken for renovation and reopening of the Bhimpur PHC. According to the locals, if somebody gets ill suddenly, then he/she will never get any primary treatment from the PHC or SC. In most cases, they take the patient to the BPHC but because of excessive distance and inadequate mode of transportation, the patient(s) are often found dead on the way to BPHC.

\section{Case II}

Rudranagar PHC, located in proper Rudranagar is about $10 \mathrm{kms}$ away from the BPHC. It was the PHC amongst the four PHCs in Murarai-II C.D.Block, which was in working order. However, it is almost a year that the PHC has been closed because of some nuisance incidents that took place between the governing authority and local inhabitants. According to the opinions of the locals and health workers, the Block Primary Health care Centre bears a lackadaisical attitude to improve the situation. Even the BPHC have withdrawn the Medical Officer (MO) of the Primary Health care Centre to accommodate the paucity in the manpower. According to the $\mathrm{SC}$ and $\mathrm{PHC}$ (Rudranagar), the medical officer (MO) of BPHC never visited the centre on a regular basis. He used to visit once in three months, that too, after repeated requests was being made by the $\mathrm{PHC}$.

Table 12: Factors Dominating the Obstacle Score Behind Provision of Maternal Health care Services (Pearsonian Product Moment Correlation Matrix), Murarai-IIC.D.Block, BirbhumDistrict, 2015

\begin{tabular}{cccccc} 
Parameters & $\mathrm{O}_{1}$ & $\mathrm{O}_{2}$ & $\mathrm{O}_{3}$ & $\mathrm{O}_{4}$ & $\mathrm{O}_{5}$ \\
\hline $\mathrm{O}_{1}$ & 1 & $0.94^{* *}$ & 0.43 & -0.58 & -0.59 \\
\hline $\mathrm{O}_{2}$ & 1 & 0.66 & -0.63 & -0.63 \\
\hline $\mathrm{O}_{3}$ & & 1 & -0.24 & -0.24 \\
\hline $\mathrm{O}_{4}$ & & 1 & $1{ }^{* *}$ \\
\hline $\mathrm{O}_{5}$ & & & 1 \\
$\begin{array}{c}\text { Note: Correlation is significant at the } \mathbf{0 . 0 5} \text { level (2-tailed) } \\
* * \text { Correlation is significant at the } \mathbf{0 . 0 1} \text { level (2-tailed) }\end{array}$
\end{tabular}

Interrelationship between the Parameters of Obstacle Score in Provision of Maternal Health Care Services and Extraction of Dominant Factor in the System

From Table 10, it is clear that there is significant positive association between two pairs of variables in the correlation matrix-bad road communication and no mode of communication to the remote places sharing the " $r$ " value of 0.94 and population pressure and inadequate man power (here, the number of ASHAs) bear significant correlation (1) (Table 12). Bad road communication $\left(\mathrm{O}_{1}=0.90\right)$ and no mode of communication to the remote places $\left(\mathrm{O}_{2}=0.98\right)$ are the dominant factors in the first PCA, which explains $62.63 \%$ of the total system, where population pressure and inadequate manpower are guides the system negatively. This means the obstacle score can be reduced in the sufferer G.Ps. by improving road 
communication and increasing the mode of transportation, conversely by reducing the excessive population pressure or by distributing the excess population load with increased number of manpower. The first and foremost requirement is to increase the accessibility and mode of communication (Table 13).

\section{Table 13: Factors Dominating the Obstacle Score Behind Provision of Maternal Health Care} Services (Extraction of Principal Components with Cumulative Percentages of Variance), Murarai-IIC.D. Block, Birbhum District, 2015

\begin{tabular}{cccccc}
$\begin{array}{c}\text { PCA ( Variance } \\
\text { explained) }\end{array}$ & $\mathrm{O}_{1}$ & $\mathrm{O}_{2}$ & $\mathrm{O}_{3}$ & $\mathrm{O}_{4}$ & $\mathrm{O}_{5}$ \\
\hline PC-1 (62.63\%) & 0.90 & 0.98 & 0.66 & -0.76 & -0.76 \\
\hline PC-2 (26.39\%) & 0.05 & 0.14 & 0.50 & 0.64 & 0.64 \\
\hline
\end{tabular}

Test of Significance in Modelling the Provision and Utilisation of Maternal Health Care

\section{Services}

From the significance test, it is evident that underserved score have significant correlation with the paucity index of MHCS's utilisation. Therefore, the null hypothesis has been rejected as the $t_{0.05}<3$ at degree of freedom (df) $=7[(9-2)=7]$. It means that underserved

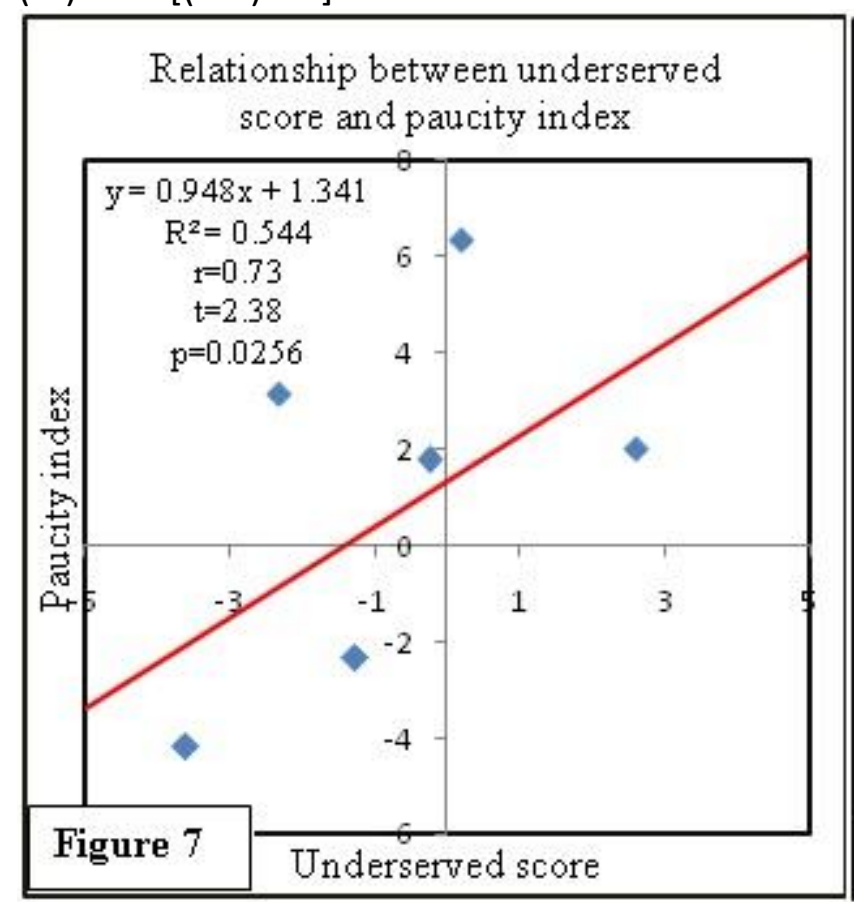

condition have direct significant impact on the inadequate utilisation of MHCSs as the p-value is $<0.05$. In a way, it can be claimed that there is not much significant correlation between obstacle score and paucity index, as the $t_{0.05}>$ 1.74 at $d f=7$ and the $p$-value is $>0.05$. Hence, the second null hypothesis cannot be rejected under such condition (Table 14).

Relationship between obstacle score and paucity index

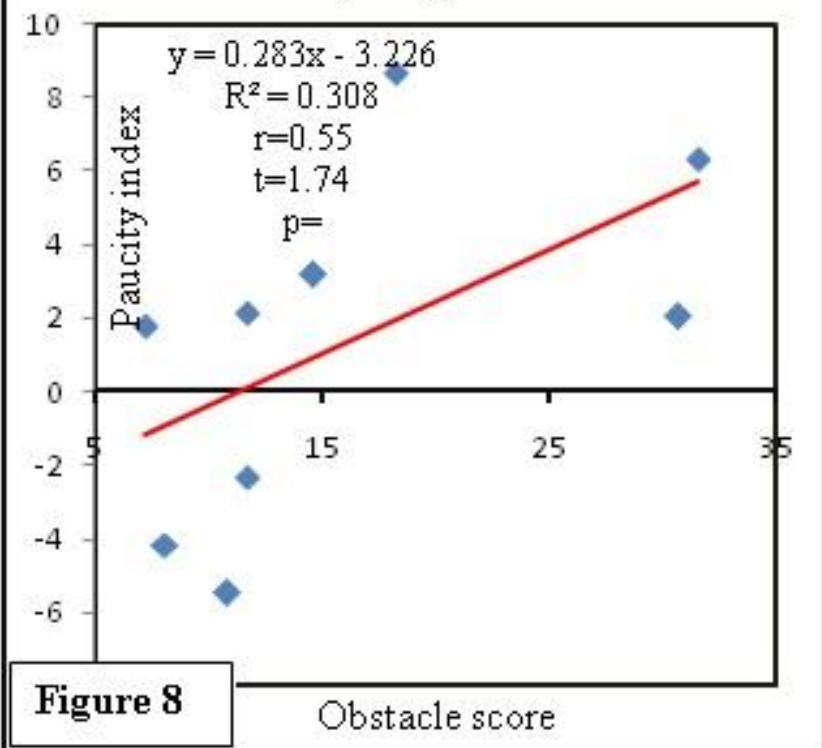

Relevance of Dependency on Underserved Score and Obstacle Score in the Utilisation of Maternal Health Care Services (Paucity index)

$$
\text { Student " } t \text { " test: } T=\left[r \times\left\{\sqrt{\left.\left.(n-2) /\left(1-r^{2}\right)\right\}\right]}\right.\right.
$$

Relevance of Dependency on Road Network (Accessibility) in the Provision of Maternal Health Care Services

Overall, it is clear from the significance test that accessibility score have significant correlation with the underserved score of MHCS's provision, paucity index of MHCS's utilisation and obstacle score behind the provision of MHCSs (Figures 7 and 8). Thus, all the three null hypothesis has been rejected as the $t_{0.05}<3$ at degree of freedom (df) $=7$ [(9-2) =7]. It means that accessibility index have direct significant impact on the underserved scenario, paucity 
index and obstacle score of MHCSs as the $p$ - value is $<0.05$ in all the three cases (Table 15).

Table 14: Table for Significance Test in Modelling the Provision and Utilisation of Maternal

Health Care Services, Murarai-II C.D.Block, Birbhum District, 2015

\begin{tabular}{cccccc}
$\begin{array}{c}\text { Independent } \\
\text { variable }\end{array}$ & $\begin{array}{c}\text { Dependent } \\
\text { variable }\end{array}$ & $\begin{array}{c}\text { Correlation } \\
\text { coefficient } \\
(\mathrm{r})\end{array}$ & $\begin{array}{c}\text { Computed } \\
\text { " } \mathrm{t} \text { " Value }\end{array}$ & $\begin{array}{c}\mathrm{t} \text { " value at } 0.05 \\
\text { \% significance } \\
\text { level }\end{array}$ & $\mathrm{p}$-value \\
\cline { 1 - 3 } $\begin{array}{c}\text { Underserved } \\
\text { score }\end{array}$ & Paucity index & 0.73 & 2.38 & 2.37 & 0.0256 \\
\cline { 1 - 3 } & & 0.55 & 1.74 & & 0.1250
\end{tabular}

Source: Computed by the Author, 2015-2016,

Source of Tabulated Value: Sarkar (2013)

Table 15: Table for Significance Test in Modelling the Provision and Utilisation of Maternal Health Care Services Depending Upon the Accessibility and Connectivity index, Murarai-II

C.D. Block, Birbhum District, 2015

\begin{tabular}{|c|c|c|c|c|c|}
\hline $\begin{array}{l}\text { Independent } \\
\text { variable }\end{array}$ & $\begin{array}{c}\text { Dependent } \\
\text { variable }\end{array}$ & $\begin{array}{c}\text { Correlation } \\
\text { coefficient } \\
(r)\end{array}$ & $\begin{array}{l}\text { Computed } \\
\text { "t" Value }\end{array}$ & $\begin{array}{c}\text { "t" value at } 0.05 \\
\% \text { significance } \\
\text { level }\end{array}$ & $\mathrm{p}$-value \\
\hline \multirow{3}{*}{$\begin{array}{c}\text { Accessibility } \\
\text { index (Saxena, } \\
\text { 2012) }\end{array}$} & $\begin{array}{l}\text { Underserved } \\
\text { score }\end{array}$ & 0.71 & 2.68 & \multirow{3}{*}{2.37} & 0.0311 \\
\hline & Paucity index & 0.92 & 6.21 & & 0.0004 \\
\hline & Obstacle score & 0.77 & 3.19 & & 0.0152 \\
\hline
\end{tabular}

Source: Computed by the author, 2015-'16,

Source of Tabulated Value: Sarkar (2013)

\section{Conclusion}

The aforesaid analysis unravels an amicable interpretation about the predominant position of distance in the utilisation of MHCSs. There is a strong significant impact of accessibility index on the paucity index, underserved score and obstacle score (Ghosh and Mistri, 2016). Hence, it clearly reveals the fact that distance has a negative impact on utilisation of MHCSs. The empirical survey bears evidence with the fact that distance directly influences the utilisation of MHCSs and a very important factor among the independent variables, which influences the utilisation of MHCSs. Amongst the other major factors, insufficiency in postnatal check-ups exhibits significant relationships with the utilization of MHCSs. Factor like- people, who have to travel more than two kms to avail the health facility, is the prime factor to assess the scenario of insufficiency in provision of MHCSs. It can therefore be said that the effect of distance in the utilisation of maternal health care services are functions of time and cost of travel (Gage \& Calixte, 2006) along with undulating topography, poor, unpaved road conditions, inadequate connectivity and accessibility (Ghosh and Mistri, 2016; Sarma and Bhattacharyya, 2015; Akhtar \& Izhar, 2010; Toan et al., 2002; Vissandjee et al., 1997; cited in Gage \& Calixte, 2006;). It can be argued that there is a strong positive correlation with parameters such as villages without ASHAs and villages beyond two kms serve zone of each SC. Percentage of PNC with institutional delivery without being accompanied by ASHA and percentage of PNC without any visit by ASHA are the paramount factors in the paucity index, portraying the paucity in the utilisation of the maternal health care service. Thus, the access to service is strongly dependent on accessibility and distance. The major obstacles behind the provision of services are bad road conditions 
and inadequate modes of communication towards the remote areas. During rainy seasons, the roads are not passable at all, which makes the situation even worse for the villagers to access the health facilities. The situation is infuriating for the proper delivery of services and therefore, enhances the event of home delivery in the remote villages. It is also responsible for the frequent transfer of ANMs in the remote SCs from the BPHC of the block.

For the betterment of present situation in maternal service inadequacy, more ASHAs should be positioned in remote underserved villages, which are located beyond two kms feed zone of each SC. Incorporating more ASHAs in the system will definitely have a positive reflection on the utilisation of MHCSs and will negate the imprint of dominant factors in the paucity index. People belonging to this underserved distant regions, are accustomed with the service delinquency, especially during the postnatal check-ups. It thus affects their health care seeking behaviour, especially after a viable healthy delivery. However, in long run, they are mostly compelled to face the postnatal complications induced by the less utilization of maternal health care services. Provision of more ASHAs or strengthening the manpower in these places will reduce the negative incidences of maternal health outcome and will increase the utilisation of MHCSs by reducing the paucity index. Apart from increasing manpower in underserved places, remote places must be connected with paved main road by introducing viable mode of communication. This will increase the proximity of those distant SCs from the BPHC and will enhance the accountability at the same time. It will have positive impact on the scenario of frequent transfer of ANMs, less provision and utilisation of PNC check-ups. People who belong to the underserved resource poor region often experienced less alacrity and eagerness from the health workers in managing the situations of Emergency Obstetric Complications (EOC), as they are located far from their own BPHC with almost no mode of communications, especially during night-time. Though some of the places of Mitrapur, part of Kushmore-I are in close proximity (6 to $10 \mathrm{kms}$ )to the Jangipur Hospital of Murshidabad district but in most cases people have to pay the emergency transport cost to visit another referral unit. As these areas are remote from the block primary health care centre (Paikar) and are devoid of their own panchayat ambulance facility (Nischayyan). Because of excessive distance, the drivers of Matriyan show a lackadaisical attitude to serve the emergency purpose, and ask for additional transportation cost, the victims either have to arrange some other means of transportation, that becomes very difficult especially in night times, or have to pay extra transportation charges in this situation. Thus, connecting the remote places with paved road and then enriching the health centres of those places with sufficient manpower will definitely increase the MHCSs utilisation in the study area.

\section{References}

Akhtar, R., \& Izhar, N. (2010). Global Medical Geography, Rawat Publication, Jaipur (ISBN-81-316-0198-6)

Anastasia, G. J., \& Calixte, G. (2006). Effects of The Physical Accessibility of Maternal Health Services on their Use in Rural Haiti, Population Studies 60 (3), pp. 271-288. Retrieved from http:/www.jstor.org/stable/30040492

Bhattacharyya, Rituparna (2016). An Account of India's under-5 Mortality Rate, International Journal of Social Work and Human Services Practice, 4(4), pp. 82-88, DOI: 10.13189/ijrh.2016.040402

Buor, D. (2002). Distance as a Predominant Factor in the Utilisation of Health Services in the Kumasi metropolis, GeoJournal, 56 (2), Springer, pp. 145-157

Chalkey, A. M. (2006). A Textbook for the Health Worker. New Delhi: New Age International (P) Limited, Publishers. (ISBN: 0-85226-939-0)

Datta, M., \& Nirmalya, M. (2012). A Study on Socio-demographic Correlates of Maternal Health Care Utilisation in a Rural Area of West Bengal. Global Journal 
of Medicine and Public Health1 (4), pp. 712

District Level Household and Facility Survey-3 Hirama, M.V., Toledo, F.A.L., Junior, E.C., Costa, (2010).Ministry of Health and Family Welfare. Govt.of India, New Delhi-110 011

District Level Household and Facility Survey-4 (2014).Ministry of Health and Family Welfare. Govt.of India, International Institute for Population Sciences, Deemed University, Mumbai 400088

Gage,A.J.,\& Calixte,M.G.(2006).Effects of the Lalmalsawmzauva, K.C., \& Nayak, D.K. (nd). Physical Accessibility of Maternal Health Services on their use in Rural Haiti. Population Studies, 60 (3). Taylor \& Francis, Ltd.271-288

Global Concerns Classroom (2013) .Maternal Lee, K. \& Chi, K.H. (nd). Uses of high-resolution health: How Can We Ensure That All Women Have Access to Quality Maternal Health Care. Retrieved from http://gcc.concernusa.org/content/uploa ds/2014/08/Maternal-Health.pdf

Goland, E., Dinh, T.P.H., \& Mats, M. (2012). Mache Inequality in Maternal Health Care Utilisation in Vietnam. International Journal for Equity in Health 11 (24), pp.58

Ghosh, A. \& Mistri, B. (2016).Impact of Distance in the Provision of Maternal Health Care Services and its Accountability in MuraraiII Block, Birbhum District. Space and Culture, India. 4(1), pp. 81-99. DOI: 10.20896/saci.v4i1.182

Gottlieb, P., \& Lindmark, G. (2002). WHO Indicators for Evaluation of Maternal Health Care Services, Applicability in Least Developed Countries : A Case Study from Eritrea. African Journal Of Reproductive Health6 (2), pp. 13-22. Retrieved from http://www.jstor.org/stable/3583126

Government of West Bengal. Kolkata. District Statistical Handbook, Birbhum District (2011).

Hati, K.K., \& Majumder, R. (2011).Health for Development: A District Level Study in West Bengal. Online at https://mpra.ub.unimuenchen.de/45849/
MPRA Paper No. 45849, posted 5 April 2013 12:04 UTC

K.B., \& Quadros, J.P. (2010). Q-Mode and

R-Mode Factor Analysis in Quantitative Studies of Microfossils of the Late Quaternary in Sediments from the Brazilian Continental Margin. University of São Paulo, Oceanographic Inst., Lab. Paleoceanography of the South Atlantic (LaPAS), pp. 41-49

Maternal Health Care Utilisation in India: Role of Surface Road Networks. Pp.1-16. Retrieved from iussp2009.princeton.edu/papers/90093 imagery for urban transportation applications: Quantitative indices extraction approaches. Retrieved from http://www.isprs.org/proceedings/XXXV/ congress/comm7/papers/199.pdf

I, G.(2010). Maternal Health: Investing in the Lifeline of Healthy Societies \& Economies. Africa Progress Panel, P.O.B. 157, 1211 Geneva 20, Switzerland. Retrieved from http://www.who.int/pmnch/topics/mater nal/app_maternal_health_english.pdf

Mahmood, A.(2002).Statistical methods in geographical studies. New Delhi: Rajesh Publications India. ISBN: 81-85891-17-6.

Mamdani, M. \& Bangser, M.(2004). Poor People Experiences of Health Services in Tanzania: A Literature Review. Reproductive Health Matters (RHM), 12 (24), pp. 138-153, Retrieved from http:/www.jstor.org/stable/3776589

Mavalankar, D, V., Vora, K.S., Ramani, K.V., Raman, P., Sharma, B., \& Upadhyaya, M. (2009). Maternal Health in Gujarat, India: A Case Study. Journal of Health, Population and Nutrition 27 (2), pp.235248. Retrieved from http://www.jstor.org/stable/23499526

Murad, A.A.( 2007). Creating a GIS Application for Health Services at Jeddah City.Computers in Biology and Medicine. Elsevier Science Ltd. ,Great Britain.

37. 
doi:10.1016/j.compbiomed.879-889. Retrieved from www.intl.elsevierhealth.com/journals/co $\mathrm{bm}$

Obaid,T.(2011). Deadly delivery: The Maternal Sarma, J.B. and Bhattacharyya, R. (2015). Half Health Care Crisis in the USA, One Year Update Spring 2011.Amnesty International · Demand Dignity Campaign, 5 Penn Plaza, 16th FI · New York, NY- Satia, J.K., Misra, M.,Arora,R., \& Neogi. S. (2014). $10001 . \quad$ Retrieved from http://www.amnestyusa.org/sites/default /files/pdfs/deadlydelivery.pdf

Park, K., (2013). Preventive and Social Saxena, H. M. (2012).Transport geography. Medicine. $22^{\text {nd }}$ Edition.M/s Bandarsidas Bhanot Publications. Prem Nagar, Jabalpur-482001 (ISBN No. 978-93-8221902-6)

Paruzzolo,S., Mehra, R., Kes, A., \& and Ashbaugh, C.(2010). Poverty and Gender Inequality. To Improve Maternal Health. International Centre for Research on Women. New Delhi - 110024 India. Retrieved from https://www.icrw.org/files/publications/T argeting-Poverty-Gender-InequalityImprove-Maternal-Health_0.pdf

Purohit, B.C., \& Siddiqui, T.A.(1994). Utilisation of Health Services in India, Economic and Political Weekly 29(18): 1071-1080. Retrieved from World Bank Group (2015). Trends in Maternal hhtp://www.jstor.org/stable/4401139

Raza, M., \& Aggarwal, Y.(1999).Transport Geography of India: Commodity Flows and the Regional Structure of the Indian Economy. New Delhi: Concept Publishing Company. ISBN 81-7022-089-0

Rana, K., Santra, S, Rafique, A., Mukherjee, A. \& Sengupta, A. (2005). The Delivery of Primary Health Services: A Study in West
Bengal and Jharkhand. The Pratichi Health Report: With an Introduction by Amartya Sen. Pratichi Trust. Delhi. India.110091 (ISBN 81-88297-03-8. 1-108) Empty or half filled? Notes on Universal Health Coverage in Northeast India, The Clarion, 4 (1), pp. 154-184. Innovation in maternal health: Case study from India. SAGE Publication, New Delhi, (ISBN-978-81-321-1310-2, PB).

Rawat Publication. Jawahar Nagar, Jaipur,India, pp. 54-79, (ISBN-81-7033945-6)

Sarkar, A. (2013). Quantitative Geography: Techniques and Presentations. Orient Blackswan (ISBN- 978812505266 1)

Singh, P.K. ( $8^{\text {th }}$ March, 2016). Because the Newly Born Deserve Better. The Statesman. Retrieved from http://www.thestatesman.com/news/opi nion/because-the-newly-born-deservebetter/128402.html

Thaddeus, S. \& Maine, D.(1994). Too Far to Walk: Maternal Mortality in Context. Elsevier Science Ltd. ,Great Britain, 38 (8), 02779536/94, pp. 1091-1110. Mortality:1990 to 2015, Estimated by WHO UNICEF, UNFPA, World Bank Group and The United Nations Population Division, Department of Reproductive Health and Research, World Health Organisation.

World Health Organisation (2015). World Health Statistics 2015. ISBN 9789241564885 ISBN 9789240694439 